\title{
"Computer Games Can Get Your Brain Working": Student Experience and Perceptions of Digital Games in the Classroom
}

Catherine Beavis (corresponding author)

Professor of Education

School of Education and Professional Studies

Griffith University, QLD, Australia, 4222

Telephone:+61 (0) 755528267

Email: c.beavis@griffith.edu.au

Sandy Muspratt

Honorary Research Fellow

School of Education

The University of Queensland

St Lucia, QLD, Australia, 4072

Telephone: +61415481906

Email: sandy.muspratt@optusnet.com.au

Roberta Thompson

PhD Scholar

School of Education and Professional Studies

Griffith University, QLD, Australia, 4222

Telephone:+61 (0) 755529786

Email:r.thompson@griffith.edu.au

\section{Acknowledgements}

This work was supported by the Australian Research Council under Linkage Grant LP110200309: Serious Play: Using digital games in school to promote literacy and learning in the twenty first century

We acknowledge the students and teachers in the six Queensland schools who are Industry Partners in this research and the Serious Play Research Team: Catherine Beavis, Michael Dezuanni, Joanne O’Mara, Leonie Rowan, Sarah Prestridge, Jason Zagami, Yam San Chee. Research Assistance: Roberta Thompson, Christy McGillivray and Colleen StielerHunt. Statistical consultant: Sandy Muspratt. Additional research assistance: David Elliot, Monash University. 


\title{
“Computer Games Can Get Your Brain Working”: Student Experience and Perceptions of Digital Games in the Classroom
}

\begin{abstract}
There is considerable enthusiasm in many quarters for the incorporation of digital games into the classroom, and the capacity of games to engage and challenge players, present complex representations and experiences, foster collaborative learning, and promote deep learning. But while there is increasing research documenting the progress and outcomes of gamesbased learning, relatively little attention is paid to student perceptions and voice. In order to effectively target games-based learning pedagogy, it is important to understand students' previous experience, if any, of the use of games in the classroom, and what they made of these. In this paper, we present findings from a survey of 270 primary and secondary school students in Year Levels four to nine (aged nine to 14) in six Queensland schools at the start of a three-year Australian Research Council project researching the use of digital games in school to promote literacy and learning.
\end{abstract}

Keywords: computer and videogames, digital games; games-based learning; digital literacy; pedagogy; student perceptions

\section{Introduction}

The enthusiasm in many quarters for the incorporation of digital games into the classroom - videogames, console games, phone and iPad games and the like - is linked to a cluster of claims, hopes and observations about the capacity of games to engage and challenge players, to present complex and challenging representations and experiences, to foster deep and collaborative learning, promote a range of literacy and learning practices (Facer 2002, Gee 2003; Shaffer et al. 2005), and meet the mindset and needs of a generation of students which has never known life without ICT (OECD 2009, NMC 2013). Yet as Bourgonjon et al. (2010) note, while arguments for games as embodying "new educational approaches" and "operational translations of contemporary learning theories" (1145) presuppose the importance of intention and agency on the student's part, for the most part it is teachers, rather than students, who make decisions about the use of 
Learning, Media \& Technology

technology in the classroom. Student voice and student acceptance are often missing in considerations surrounding the introduction of e-learning, including digital games.

In their 2013 review of games-based learning, Perrotta et al. identified a second and related absence in much games-based learning research - research "that accounts for the realities of school" (iii). In the same vein, Selwyn (2012) argues the need for researchers to take care "that the apparent novelty of the technological near-future does not seduce them into overlooking the rather more messy 'realities' of the present", and to "remember that education and technology is as much about investigating the imperfect 'state of the actual' as it is about exploring the perfected 'state of the art"' (215-6). Erstad and SeftonGreen (2013) similarly note a "mismatch between what is highlighted by policy makers and researchers as the new brave world of digital technologies through numerous 'best practices' and 'early adopters', and the conditions under which most teachers and students are operating in schools" (94).

In order to effectively target games-based learning pedagogy and interventions, it is important to have an understanding of students' previous experience, if any, of the use of games in the classroom, and what they made of these. In this paper, we present findings from a survey of 270 primary and secondary school students in Year levels four to nine (aged nine to 14) in six Queensland schools at the start of a three-year Australian Research Council project researching the use of digital games in school to promote literacy and learning ${ }^{\mathrm{i}}$. These students were part of a larger cohort that also included students in four Victorian schools which had previously been part of formal research projects investigating the use of games ${ }^{\mathrm{ii}}$, and younger children in grades prep to three (aged under nine) who were considered too young to read and interpret survey questions without adult support. Students were asked about their previous experience and expectations of games in the 
Learning, Media \& Technology

classroom prior to the project beginning. Their answers and observations provide a usefully mixed and messy picture of patterns of the use of digital games in schools, encompassing students from a range of ages and school contexts, with varying degrees of interest and experience in playing games in and out of school, addressing games and gameplay activities across a range of curriculum areas.

\section{Background and methodology}

\subsection{The project: Introducing Serious Play}

Serious Play: Using digital games in school to promote literacy and learning in the twenty first century is an Australian Research Council project that explores the implications for literacy, learning, curriculum, pedagogy and assessment when digital games are introduced as part of formal learning and curriculum at school. The project operates in partnership with Griffith University, Queensland University of Technology, Deakin University, the National Institute of Education in Singapore, six Queensland schools, and four Victorian schools. Industry partners include the six Queensland primary and secondary schools, and the Department of Education and Early Childhood Development (DEECD), Victoria. Teachers remain more or less constant across the project, but in most instances the student cohort changes from year to year.

In the course of the project, working in conjunction with the research team, teachers undertake four school-based research explorations within their curriculum units, attend six Professional Learning days (two per year), complete a short survey, and participate in an online Professional Learning site. Data is collected using a range of methods including surveys, focus group interviews, field notes from classroom observations, video recordings, classroom artefacts, and student-reported data gathered out of school (Other, 
Learning, Media \& Technology

Other and Author A, under review). Data is also gathered from teachers, in relation to their experiences, expectations and observations, together with curriculum planning and reflections, through a similar set of data generating processes (Author A, Others and Author C, 2014).

At the beginning phase of this project, participating students in both states completed a paper-based survey. The purpose of this survey was to collect baseline information about the students' experience with computer games at school. As outlined above, four of the 10 schools had previously participated in research into games-based learning with members or Industry Partners in the current research team. In this paper, we focus on the experiences and perceptions of students at in the remaining six schools.

\subsection{Survey Design}

The survey was designed to gather information about students' use of and their attitudes towards the use of games in the classroom, including the games they have played in the classroom, games they have made in the classroom, and the formal study of games. In addition to items requiring answers along a Likert scale, free text options were also included, enabling the collection of additional data in qualitative form.

The survey was distributed to schools during Semester One, 2012. It addressed the following areas:

- Background data - the students' gender, age, year level.

- $\quad$ Games played outside school - favourite games, how often students played games; social dimensions of game playing. 
Learning, Media \& Technology

- Games in the classroom - the games students play; the games they like and dislike and why; the curriculum areas in which the games were used; what the students thought games would be good at teaching and what they thought could be problems associated with using games in the classrooms.

- A set of questions reflecting the three foci of classroom-based work: games used to support learning in curriculum areas; the study or analysis of games per se; and making games.

Following the initial collation of data, lists of games identified by the students were double checked to take account of different spelling, punctuation, and different versions of the same game. Free text answers were transcribed and coded for themes and lexical collocation around key terms.

\subsection{Participants}

The students represented in this paper come from schools where the schools themselves, or teachers at those schools, have a pre-existing interest in working with digital games. Participating schools opted in as Industry Partners, contributing access to the school's technologies and teachers' time. All schools represented in this paper were located in metropolitan centres. Prior experience with games-based learning varied between schools. Some teachers had used games previously with students, and some students had experienced the classroom use of games in previous years. A number of teachers had experimented with games-based learning in varying ways, with games ranging from Commercial Off the Shelf games, such as Minecraft, Educational 'games' such as Mathletics or Gold Rush, Educational websites, such as Kahootz or Scootle, and games-making software such as Game-maker in subjects like Media and IT. The opt-in nature of this group, and the individual school and classroom contexts in each of the 
Learning, Media \& Technology

participating schools, mean that findings relate to these students specifically. We can point to the presence of a feature in the sample of students but are unable to indicate the extent to which the feature might be present in a population of students more generally.

A total of 270 students completed the survey. Of these, 101 or $38 \%$ were female; 168 or $62 \%$ were male; and one student did not answer the question. Not all students answered all questions. Students came from 12 classrooms located across the six schools. The students were located in five Year Levels ranging from Year Level 4 through to Year Level 9, with the majority (125 or 49\%) were located in Year Level 5. Ages ranged between eight and 14, with the largest group (109 or $42 \%$ ) aged $10,13 \%$ aged nine, $11 \%$ aged $11,7 \%$ aged $12,18 \%$ aged 13 and $9 \%$ aged 14 .

\section{Findings}

\subsection{Games outside school}

Once demographic data was established, the survey began by asking students how often they played games out of school. Consistent with other studies of usage levels amongst children and young people at this age (ABS 2012, iGEA 2012), hours of play in most instances were found to be relatively modest. Of those who answered this question, 114 or $44 \%$ reported playing "Sometimes" (approximately $1-4$ hours per week) and 8\% "Never". A substantial number, however, (38 or 15\%) reported playing "A lot" (10 or more hours per week).

Students were asked to nominate three favourite computer games. Figure 1 shows the top ten games. Top of the list came Minecraft and Call of Duty. Other 'games' that are 
Learning, Media \& Technology

reasonably popular included Mars Explorer, Mathletics, Temple Run, Halo, and Reading Eggs.

A number of points are worth noting here. The naming of two very different games as favourites - Minecraft and Call of Duty - indicates the diversity of experiences and pleasures amongst the group of nine to 14 year olds surveyed. Also noteworthy is that the list includes many 'school' games - educational games or learning objects rather than commercially available games. It may be that students misunderstood the question, and took it as referring to games in school. Alternately, it may be the case that these 'games' were either the only ones they knew, or were indeed the ones they most liked to play. Further down the list (not shown here) came a stream of casual games - Poptropica, Subway Surfer, Parking Mania, Cooking Mama, Angry Birds and the like, none attracting high numbers but as a group notable for their popularity. This finding is consistent with high levels of usage of casual games amongst the population more generally (Juul 2009).

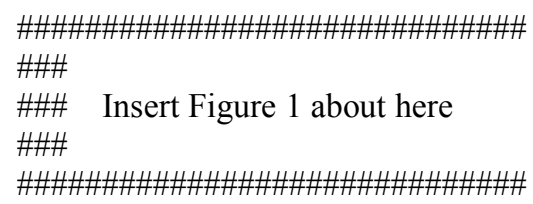

Enjoyment is central to game play. Students were asked to indicate what they enjoyed about playing games (Figure 2), utilising a list of items from our previous research with secondary school students (Author B and Other) that adapted early motivational categories developed by Bartle (1996) and Yee (2005) together with literature on gamesbased learning to identify common features associated with learning through games (Papert 1996, Gee 2003, Squire 2006, Francis 2006). Phrasing and terminology were modified to 
Learning, Media \& Technology

reflect language and concepts accessible to students of this age, with the familiar term 'computer games' adopted as the overall term to encompass digital games.

As in our earlier study, we were interested to learn more about the value students placed on the competitive, creative and social aspects of games in their out of school play.

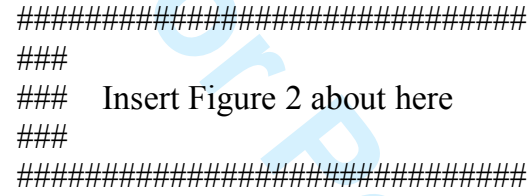

Competition and getting ahead figured highly as favourite aspects, as shown in the top half of Figure 2, but Discovery rated highest of all, with 224 of the 269 students who completed this question naming it as the most important dimension. Social aspects helping other players, being part of a team, becoming friends in the game, chatting with other players or getting to know them - are spread throughout, suggesting they are of variable importance to students within this group. While students were not asked to give reasons or comment on their choices, these preferences perhaps reflect the age group targeting by the survey, and the relatively young age of most respondents. The small number of students who named making avatars as most important is consistent with Australian Bureau of Statistics (ABS) findings in 2012 where only 7.2\% of children aged five to 14 were engaged in 'creating online content' as part of their online engagement. At the same time, however, this was the fastest growing area of activity. These patterns of preference provide interesting pointers to the kinds of games, game play opportunities and experiences most likely to be of interest to students in project schools.

\subsection{Games inside School}


Learning, Media \& Technology

The bulk of the survey was concerned with students' previous experience with games in classroom contexts, their views about the value and suitability of this, and their sense of the potential of games to support learning in school.

\subsubsection{Previous experience with games in the classroom}

The majority (93\%) believed that games can be used to teach in classrooms. In the sample, 228 or $87.0 \%$ of students had already used games in the classroom, and were well placed to report on what they had done, and how valuable they felt these activities had been. Students who responded "No" to the question about using games in the classroom were directed to exit the survey at this point. Most did, but a substantial number did not and came back into the survey at various points. From the next few questions in the survey, 37 students were dropped from consideration. Thus the sample size was reduced to 233 .

\subsubsection{Games used in the classroom}

Students were asked to nominate three games that they had used in the classroom. In the sample, 189 students (out of 233) nominated three games. Of those who did not nominate three games, 24 nominated two games, 19 nominated one game, and one student did not nominate any games. Figure 3 shows the number of nominations for the names of games used in the classrooms for the sample. Given the very specific nature of survey participants, it is likely that whether or not any given game had been played at school depended on teacher and curriculum preferences operating in any given classroom. Figure 3 shows the top 10 'games' that students named. Interestingly, of these, the vast majority are 'educational' rather than commercially popular games, and might not warrant the name 'games' at all, but are rather, educational learning tools or effectively textbooks on line. 
Learning, Media \& Technology

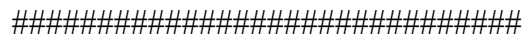

\#\#\#

\#\#\# Insert Figure 3 about here

\#\#\#

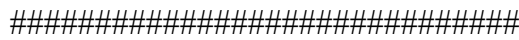

\subsubsection{Most and least favourite classroom games.}

In addition, students were asked to nominate the game they liked the best, and the game that was their least favourite. Figure 4 shows the top 10 games that students in the sample named as ones they liked the best and the least.

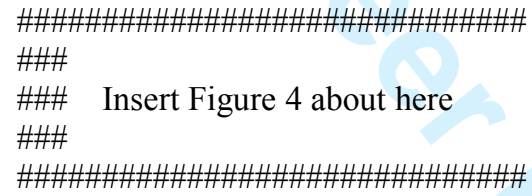

We cannot read too much into the figure. A game's appearance or otherwise in a list and its position in a list depend on the games being played by students and by how many students. Nevertheless, the figure tell us that among the games that were nominated as being used in the classroom, some students liked them, but other students did not like those same games. The same three games figure at the top of both lists.

In two related free text questions, students were asked to identify what they liked best about their favourite classroom game. Comments related to opportunities for agency ('I can roam free to be me'); learning ('you learn differently and it's fun'); the degree of difficulty ('it challenges your mind'); engagement with friends ('you can chat and have fun') and consumption and accumulation of materials ('you earn gold and buy food like in the gold rush'). Things they did not like included low interest levels ('we did it for half an hour, boring, horribly boring'); the pace of the game ('it was really slow and I didn't get 
Learning, Media \& Technology

it'); a dislike of the content field or genre ('you have to do maths'); and that it was not really a game, but work ('because it just asks you questions not games’).

\title{
3.3. Three foci for games-based learning.
}

Teachers were invited to develop units within the project in one of three areas: Using games to support learning in curriculum areas, Making games, and Studying games in ways analogous to the study of films, novels and the like in subjects such as Media Studies or English. Teacher interest and expertise, the availability of resources, and the curriculum area in which participating teachers worked, determined individual choices and school-based project activities. Reflective of the project's focus on these three forms of learning with games, the second half of the survey asked students about their previous experiences in each of these three areas.

\subsubsection{Using games to support learning in curriculum areas}

If they had had experience of games being used in curriculum areas, students were asked to indicate the curriculum or subject area in which the games were used. They could nominate as many as was needed. English, Maths, Studies of Society and the Environment, and Technology were the four subject areas in which games were reported to have been used most often, while Drama, Languages Other than English, and Health and Physical Education were reported as the three subject areas in which games were used least.

\author{
\#\#\#\#\#\#\#\#\#\#\#\#\#\#\#\#\#\#\#\#\#\#\#\#\#\#\# \\ \#\#\# \\ \#\#\# Insert Figure 5 about here \\ \#\#\#

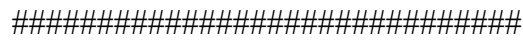


Learning, Media \& Technology

In another free text question students were asked if there was anything they did not like about using computer games in the classroom. As with previous open response questions, answers were analysed to identify major categories, with indicative comments drawn from student answers providing a more detailed picture of the nature of their concerns. Features identified by students included concerns with connectivity and technical issues ('it takes forever to load'); the quality of the games ('the main game we are allowed to use is boring and we hardly ever play computer games in the classroom'); restrictions ('you always have to play something to do with learning'); hardware access ('having to walk around the school to get a laptop') and pressure for success ('if you lose, everyone can see'). Evident in these comments, as in free text comments given earlier, is a preoccupation with managing the technology. Evident too are school-based concepts of what 'learning' might be, as also of what forms, and under what circumstances game playing in school would be allowed.

Students were asked what they thought games would be good at teaching in the classroom. They were presented with a number of options and asked to tick as many as apply. Two hundred and thirty two students answered this question, and their responses are summarised in Figure 6.

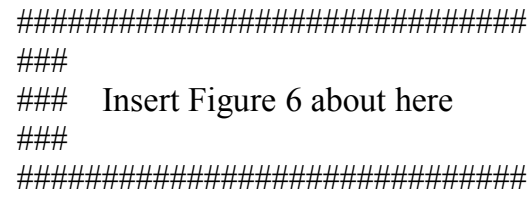

All response categories were ticked by substantial numbers of students. For the least rated item, fewer than half (115) thought that games were good at teaching 'important ideas about the topic' but considerably more (153) ticked that they were good at teaching 
Learning, Media \& Technology

'important facts'. While suggestive, whether this difference suggests students drew a distinction between factual and conceptual dimensions in curriculum areas remains frustratingly unclear. This distinction, the narrow range of 'games' students have thus far worked with in the classroom, and the patterning of other answers, is interesting in the light of other research about what games are and are not good at teaching, and about what is important but less readily accommodated or recognised within narrowly framed definitions and parameters.

In addition to being asked about what games are good at teaching, students were asked about possible problems that resulted or that could result from using games in the classroom. As was the case with the previous question, students were presented with a number of options and they were asked to tick as many as apply. This question was answered by 226 students. Figure 7 shows the problems named, and the number of times each problem area was ticked.

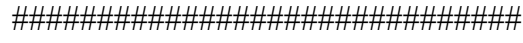 \\ \#\#\# \\ \#\#\# Insert Figure 7 about here \\ \#\#\#

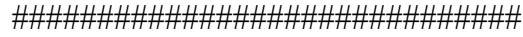

Few students believe that there would be problems associated with parents' or teachers' attitudes towards the games, and few believed that games would not be suitable for school classrooms. Larger numbers of students saw problems associated with finishing the games, however, and with the fragility of school IT infrastructure. These answers tellingly reflect free text comments from the earlier section of the survey, about the least liked aspects of the least favourite games, with a similar preoccupation with technical issues and access and the pressure for success in the question. This pattern seems also to be 
Learning, Media \& Technology

the 'other side of the coin' of the high premium on competition evident in the question concerned with elements enjoyed in out-of-school game play (Figure 2).

\subsubsection{Making Games}

As outlined earlier, classroom work within the project focussed on three areas of activity. To learn more about students' previous experience in the second of these three areas, Making Games, students were asked if they had made games in the classroom. In the sample, 32 students did not answer the question, but of the remainder, 79 (or 33\%) stated they had. Students were asked to name the software they used in making the games. Amongst those who responded, 21 students named Scratch; 10 Gamemaker; and one Unity, from a list of options presented. In addition, a large number of students had used other software to make games, including 45 who nominated Power Point and six Kahootz.

Students who had made their own computer games were asked to describe what they were like in an open response question. Answers were analysed to identify major categories, with indicative comments drawn from student answers providing a more detailed picture of what they had made, and what they liked about their games. Table 1 sets these out.

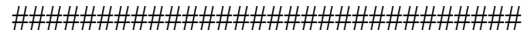 \\ \#\#\# \\ \#\#\# Insert Table 1 about here \\ \#\#\#

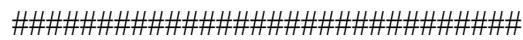

As with other areas of school-based experience identified, students' answers to a large degree reflect choices and decisions made by others, whether peers who might have introduced them to specific games in relation to favourite games (Figure 1), or as here and 
elsewhere, by the classroom context, teacher preference and subject area (Bourgonjon et al. 2010). Thus, in the 'Content Fields', the 40 students who made games in the area 'Humanities' came from a single school and had undertaken the game making as part of a unit on the Gold Rushes - a popular history topic in Australia. Other comments variously emphasis the technical and structural aspects of their games, consistent with Information Technology/Design Studies priorities, and a good knowledge of the generic features of various categories of games. While their comments suggest an evaluative awareness of what makes a game 'good', however, there is less evidence of priorities central to production in Media Education - the ability to select, construct and represent through production, concerns with representations, institutions, audiences and technologies, and of links between production and student agency (Dezuanni 2011).

\subsubsection{Studying/analysing games}

The third potential focus for classroom work was the critical analysis of games, treated as texts analogous to literary or other media forms. Students were asked whether they had studied games in the classroom. They were presented with a set of relevant topics they might have discussed, and asked to select those that applied to their classrooms. A total of 206 students answered the question. Figure 8 shows the students' responses.

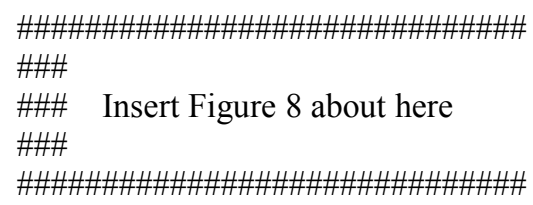

The most frequent area discussed concerned specific avatars or characters in a computer game. Other topics discussed less often but still relatively frequently included the narrative or story, 'games and their connection to other media' and 'the importance of 
Learning, Media \& Technology

games in some people's lives.' The first three of these suggest an approach to talking about games that treats them as particular formations of narrative and transmedia entertainment, while the third (games and their connection to other media) in connection also with the two that follow ('the importance of games in some people's lives, values or ideas in a computer game) also suggest a recognition of games as a significant and popular cultural form. The last two ('advertising and games' and 'whether games are bad for you'), perhaps also in conjunction with 'values or ideas in a computer game', suggest an issuesbased approach to the topic, in a context prioritising argument and critical analysis.

The data presents an interesting anomaly. A number of students selected "We don't talk about computer games", yet also selected other options as well from the answer set that suggested they did in fact talk about computer games in the classroom. Without speaking to students directly about what was intended by their response to this question, these inconsistencies cannot be resolved, however it may be that students did not regard issues such as those identified as part of a more formal discussion focussed specifically on games.

\section{Conclusions and implications}

The range of experiences of the use of digital games in the classroom described by students in this study are mixed and idiosyncratic, but at the same time paint a suggestive picture of the ways in which games are finding their way into classroom pedagogy and practice. The out-of-school games cited by students comprise a mix of popular commercial games and those designed for educational purposes. Pleasures associated with out-ofschool play, including competition, team play and discovery, are consistent with those found in other studies with players of school age and older (Yee 2005, 2007; Carr et al. 
Learning, Media \& Technology

2006). Information about students' out of school game play provides the backdrop against which their in-school experience of games may be contextualised.

A large number of students had played games of various kinds in classroom contexts, reflective perhaps of these schools' interest in participating in the research project, with teachers already exploring the possibilities of games prior to starting the sustained research. Students' experience of in-school play varied, with opportunities for engagement, socialising, challenge and accumulation highly prized, but an impatience with 'boring' games, low interest levels, tediously 'educational' content and frustrations with technological difficulties. Connections between 'fun' and 'learning' were valued where they occurred, and there was strong affirmation of things that games were good at teaching, such as 'problem solving' or 'making things interesting'. On the negative side, not all games-based activities were experienced as 'fun' or 'educational'. Other perceived problems included differing levels of expertise amongst students (and teachers) and fears about the potential misuse of games. Games had been used in a wide range of curriculum areas. For many students, this included discussions and analysis of games in English, Media and related areas, and a significant number had also made their own games. While students were cautious in their closing comments about what might and might not be achieved through games, overall the survey paints a picture of positive experiences and enthusiasm for the possibilities of games. As one student wrote 'computer games can get your brain working' while another commented 'you can learn lots of things, even though people might not think it.' The data provides a useful overview for project purposes of students' prior experiences, enabling participating teachers and the research team to target interventions appropriately. 
Learning, Media \& Technology

The survey focussed on students' experiences and perceptions rather than those of their teachers, and the degree to which it is appropriate to extrapolate from the student experiences outlined here to their teachers' purposes and practices is limited. The range of games identified by the students, the kinds of activities entailed and the subjects in which they were located, appear to be indicative of an interest on previous teachers' part in exploring games to extend understandings, motivate or reward, without these teachers necessarily having access to or knowledge of a wide range of games, and operating within the constraints imposed by classroom cultures, and curriculum and assessment regulations and parameters. The data suggests that for these students at least, the development of further classroom units, as part of the systematic exploration of games-based learning undertaken by teachers in this project, will take place against an informed, if varied, background of games-based learning and experience. While the data the survey provides is specific to these six schools, it is nonetheless suggestive in the picture it paints of broader questions and patterns raised more generally as games and games-based learning makes their way into schools. 
Learning, Media \& Technology

\section{References}

Author A, Others and Author C. 2014.

Author B and Other. 2012.

ABS (Australian Bureau of Statistics). 2012. Children's Participation in Cultural and

Leisure Activities. http://www.abs.gov.au/ausstats/abs@.nsf/cat/4901.0

Bartle, R. 1996. "Hearts, Clubs, Diamonds, Spades: Players Who Suit MUDs”. The

Journal of Virtual Environments 1 (1). http://www.mud.co.uk/richard/hcds.htm

Bourgonjon, J., M. Valke, R. Soetaert, and T. Schellens. 2010. “Student's Perceptions

About the Use of Video Games in the Classroom". Computers \& Education 54 1145-1156.

doi:10.1016/j.compendu.2009.10.022

Carr, D., D. Buckingham, A. Burn, and G. Schott. 2006. Computer Games: Text, Narrative and Play. Cambridge: Polity Press.

Dezuanni, Michael L. 2011. "Youth Media Production and Technology Skills Acquisition: Opportunities for Agency”. In International Perspectives on Youth Media: Cultures of Production and Education, edited by JoEllen Fisherkeller, 121-137. New York: Peter Lang Publishers.

Erstad, O. and J. Sefton-Green. 2013. “Digital Disconnect? The 'Digital Learner' and the School”. In Identity, Community and Learning Lives in the Digital Age, edited by O.

Erstad, and J. Sefton-Green, 87-106. New York: Cambridge University Press. 
Learning, Media \& Technology

Facer, Keri. 2002. “Computer Games and Learning: Why Do We Think It's Worth Talking About Computer Games and Learning in the Same Breath?” A discussion paper. Futurelab. http://www2.futurelab.org.uk/resources/documents/discussion_papers/Computer_Games_a nd_Learning_discpaper.pdf

Francis, R. 2006. “Towards a Theory of a Games-based Pedagogy". Paper presented at the JISC Online Conference: Innovating E-learning 2006: Transforming Learning Experiences, March 27-31.

Gee, J.P. 2003. What Video Games Can Teach Us About Learning and Literacy. New York: Palgrave.

iGEA (Interactive Games and Entertainment Association). 2012. Digital Australia 12. http://www.igea.net/wp-content/uploads/2011/10/DA12KeyFindings.pdf

Juul, J. 2009. A Casual Revolution: Reinventing Videogames and Their Player. Cambridge, Massachusetts: MIT Press.

OECD (Organization for Economic Co-operation and Development). 2009. Centre for Educational Research and Innovation (CERI) - New Millennium Learners http://www.oecd.org/document/10/0,3746,en_21571361_49995565_38358154_1_1_1_1,0

0. html

Other, other, and Author A. (Under review). 
Learning, Media \& Technology

Papert, S. 1996. The Connected Family: Bridging the Digital Generation Gap. Atlanta: Longstreet Press.

Perrotta, C., G. Featherstone, H. Aston, and E. Houghton. 2013. Games-based Learning: Latest Evidence and Future Directions. Slough, UK: NFER

Shaffer, D., K. Squire, R. Halverson, and J. Gee. 2005. "Video Games and the Future of Learning”. Phi Delta Kappan 87 (2): 104-111.

Selwyn, N. 2012. "Ten Suggestions for Improving Academic Research in Education and Technology". Learning, Media and Technology 37 (3) 213-219.

Squire, K. 2006. "From Content to Context: Videogames as Designed Experience". Educational Researcher 35 (8): 19-29.

Yee, N. 2007. "Motivations for Play in Online Games". Cyberpsychology and Behaviour $9(6): 772-775$.

Yee, N. 2005. "Motivations of Play in MMORPGs". Proceedings of the DiGRA 2005

Conference Changing Views - Worlds in Play

http://www.digra.org/wp-content/uploads/digital-library/06276.26370.pdf 
Learning, Media \& Technology

Figure Captions

Figure 1: Number of nominations for favourite game

Figure 2: The importance of competitive, creative and social aspects of games as significant elements of game play

Figure 3: Games used in the classroom

Figure 4: Games used in the classroom nominated as liked best and liked the least

Figure 5: Subject areas in which games were used

Figure 6: What students think games are good at teaching

Figure 7: Problems with using games in classrooms

Figure 8: Discussion topics about games studied in the classroom 
Learning, Media \& Technology

Table caption

Table 1: Students' games and what they liked about them. 
Learning, Media \& Technology

Table 1

Tell us about the games you made, what are they like? (75)




Learning, Media \& Technology

${ }^{\mathrm{i}}$ Author A et al. $(2012-2014)$

ii Author A, Other, Other and Other (2007 - 2009). 


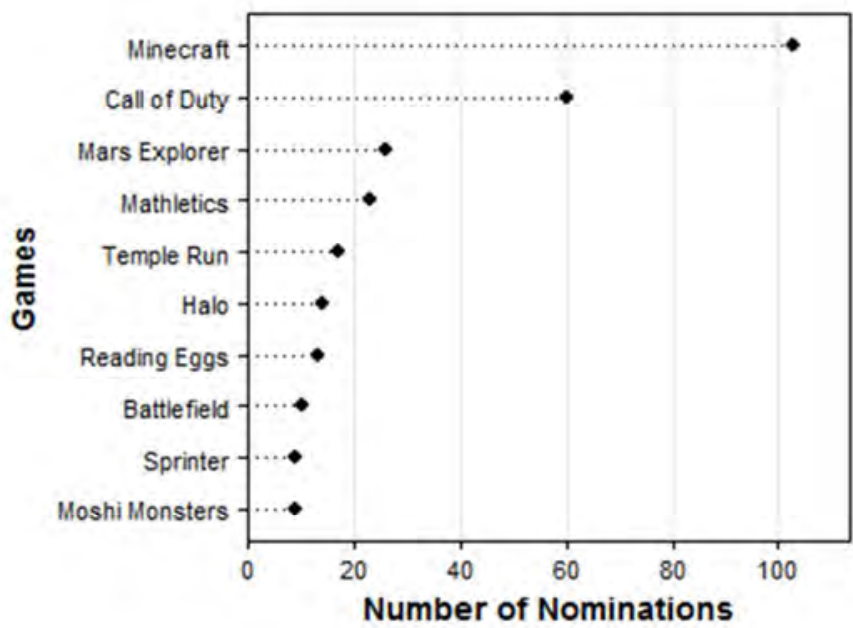

$101 \times 76 \mathrm{~mm}(100 \times 100 \mathrm{DPI})$ 


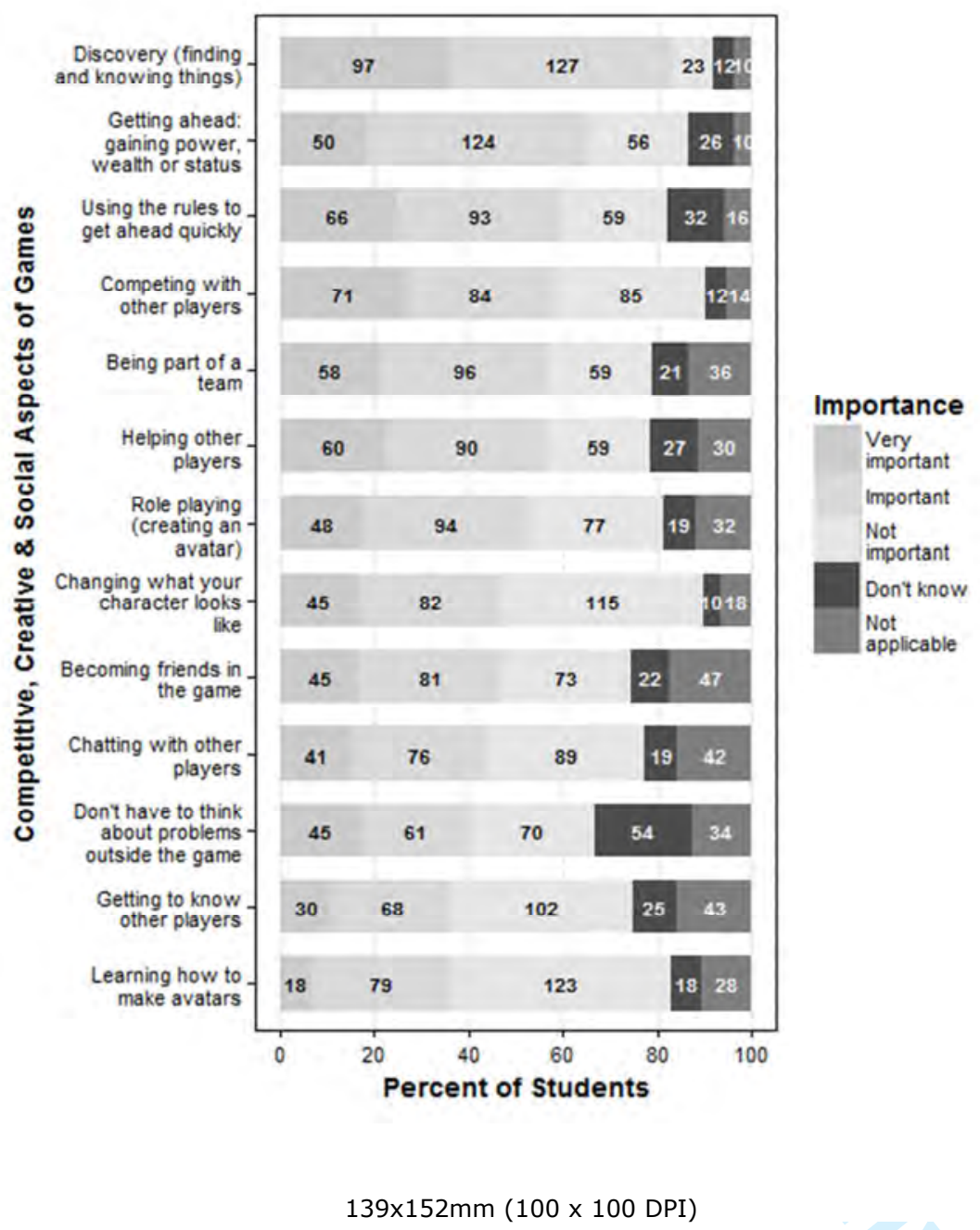

URL: http://mc.manuscriptcentral.com/lmat 


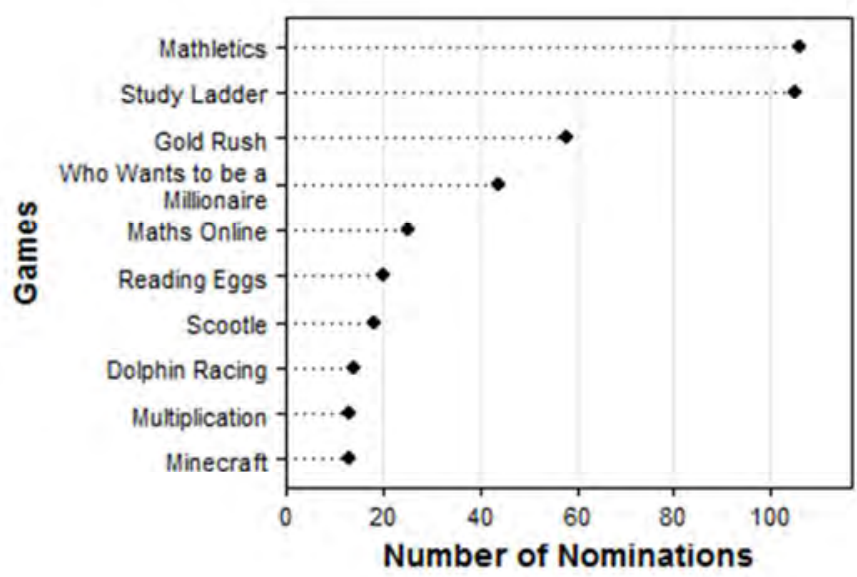

$101 \times 69 \mathrm{~mm}(100 \times 100 \mathrm{DPI})$ 


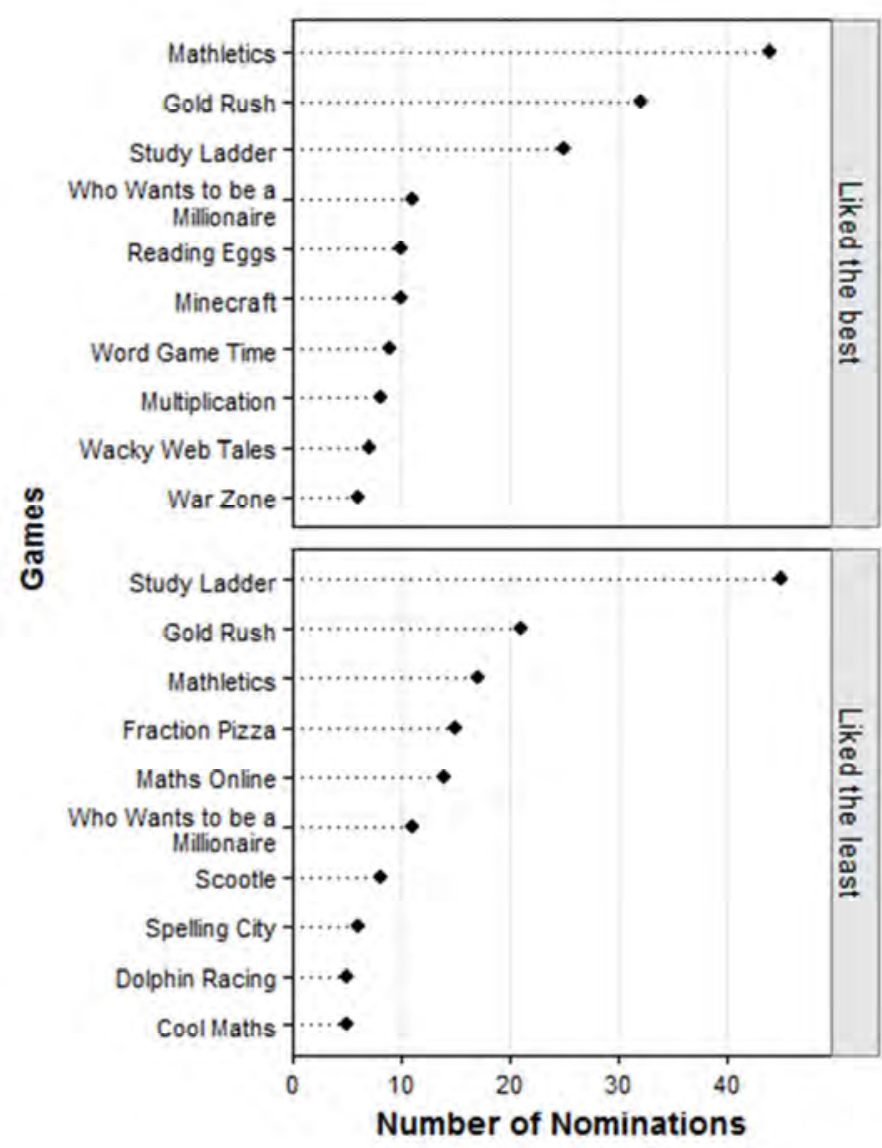

$103 \times 133 \mathrm{~mm}(100 \times 100 \mathrm{DPI})$

URL: http://mc.manuscriptcentral.com/lmat 


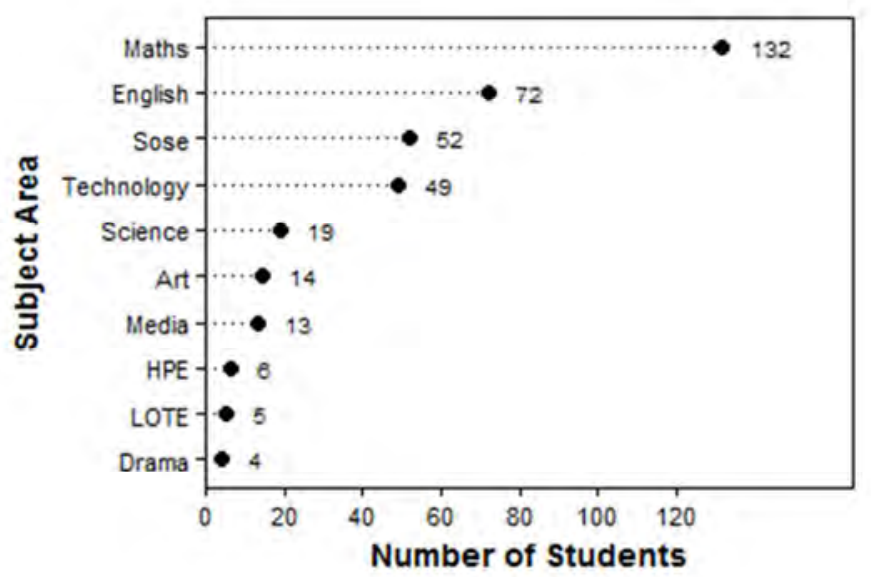

$101 \times 69 \mathrm{~mm}(100 \times 100 \mathrm{DPI})$ 


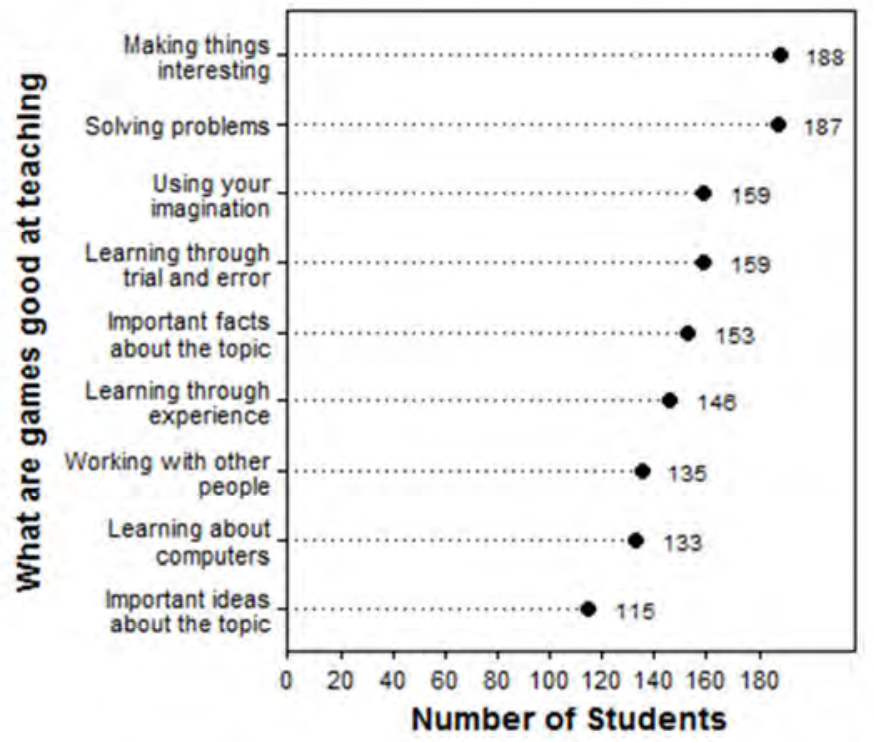

$101 \times 88 \mathrm{~mm}(100 \times 100 \mathrm{DPI})$

URL: http://mc.manuscriptcentral.com/Imat 


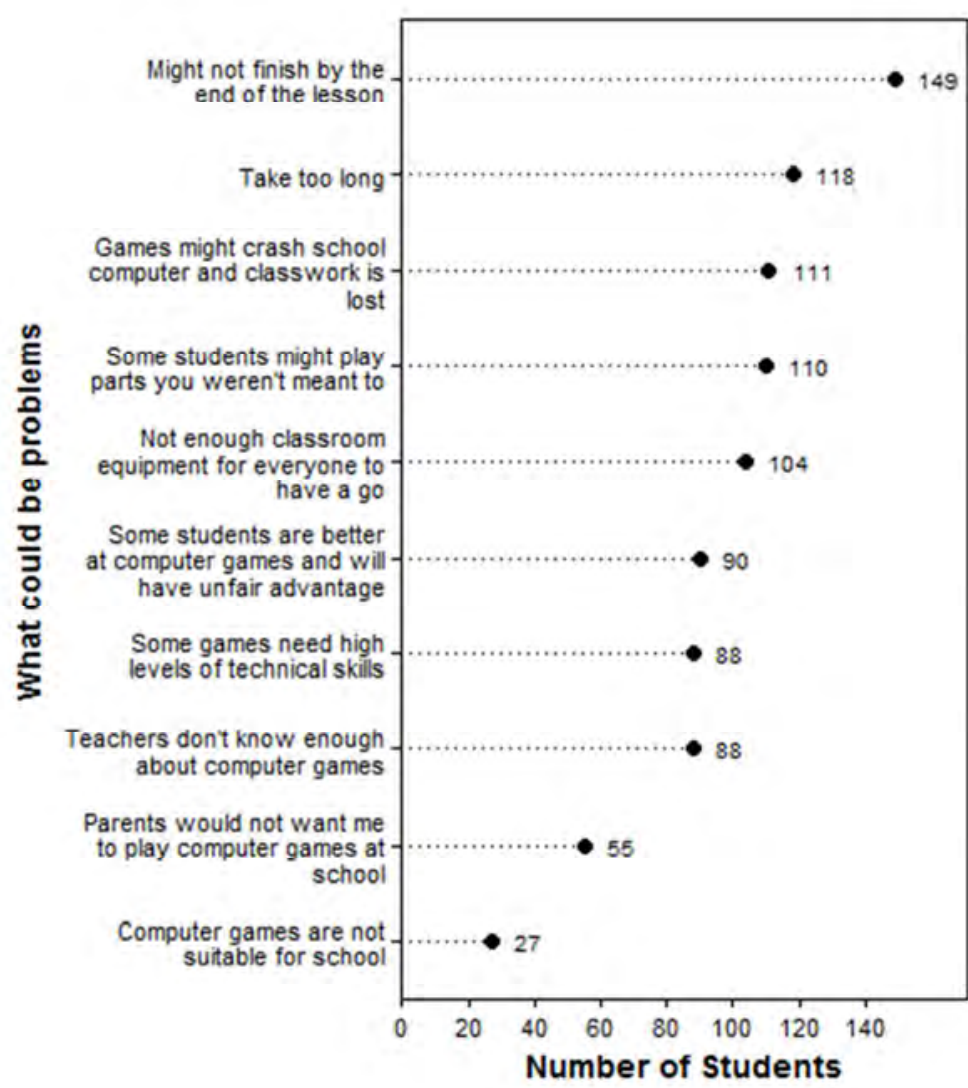

$114 \times 127 \mathrm{~mm}(100 \times 100 \mathrm{DPI})$ 


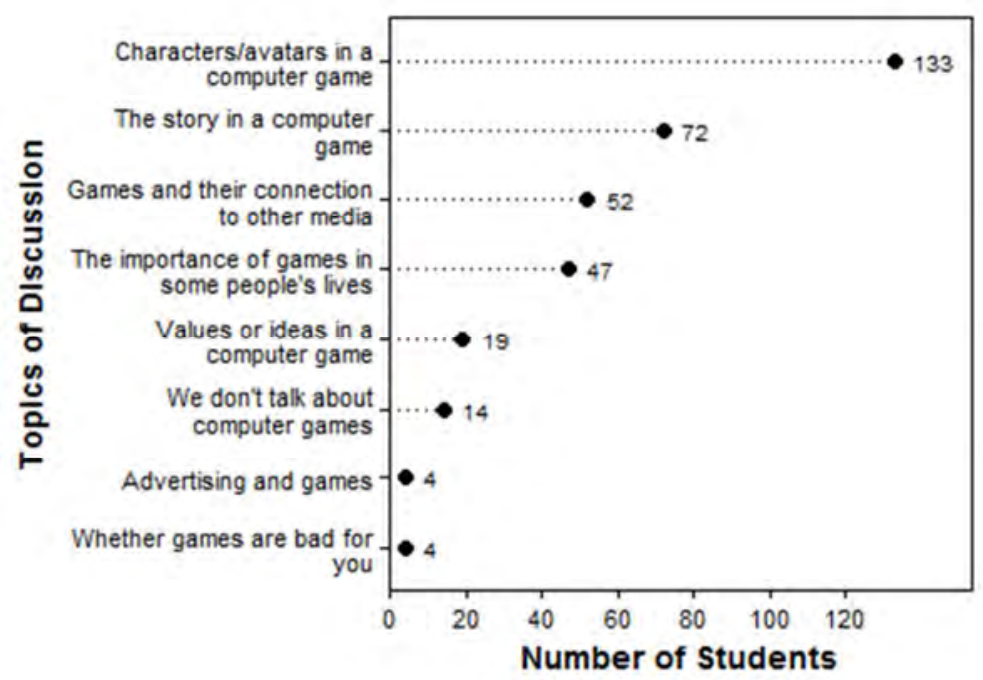

$114 \times 81 \mathrm{~mm}(100 \times 100 \mathrm{DPI})$ 